\title{
Representações do outro: estudo com imagens em livros didáticos
}

\section{Luciana Coutinho Pagliarini de Souza e Maria Ogécia Drigo}

\section{Luciana Coutinho Pagliarini de Souza ।}

Doutora em Comunicação e Semiótica - PUC/SP; pós-doutora com estágio na Universität Kassel/Alemanha. Professora do Programa de Pós-Graduação em Comunicação e Cultura da Universidade de Sorocaba (Sorocaba, São Paulo, Brasil). E-mail: luciana.souza@prof.uniso.br

\section{Maria Ogécia Drigo}

Doutora em Comunicação e Semiótica - PUC/SP; pós-doutora pela ECA/USP. Professora e Coordenadora do Programa de PósGraduação em Comunicação e Cultura da Universidade de Sorocaba (Sorocaba, São Paulo, Brasil). E-mail: maria.drigo@yahoo.com.br

\section{Introdução}

A interseção entre Comunicação e Educação contextualiza esta pesquisa. Na Comunicação, inscreve-se a imagem enquanto representação visual, compondo as mais diferenciadas linguagens. Pela natureza ecológica de sua construção, as imagens estabelecem correspondências sociais e naturais, o que favorece interações percebidas também no ambiente educacional e nos mais diversos meios, inclusive nos livros didáticos. Assim, a interface com a Educação se faz.

Considerando o fato de o livro didático - silenciosa e sutilmente - poder estar entre os meios responsáveis por propagar mensagens que envolvam a alteridade, interessava-nos compreender 0 tratamento dado ao outro engendrado em suas representações visuais. Se elas favoreciam a construção de ambientes que aproximassem as pessoas, que propiciassem a coexistência ou o contrário.

Assim, com o objetivo de refletir sobre a possibilidade da construção de ambientes que oportunizassem a vivência com o outro, ou com 
0 diferente, 0 estranho, o estrangeiro, a partir da experiência em ambientes escolares, com livros didáticos, adotamos a metodologia que será descrita a seguir. Iniciamos com os procedimentos para determinação da amostra. 0 universo de livros didáticos para a pesquisa foi obtido a partir das resenhas que constam no Guia de Livros Didáticos ${ }^{1}$ - PNDL 2012 - para as séries finais do Ensino Fundamental das disciplinas escolares: Ciências, Matemática, História, Geografia, Língua Portuguesa e Língua Estrangeira. Do total de 66 coleções, tomamos 30\% delas para formar uma amostra estratificada, o que corresponde a 20 exemplares. Dentre os critérios de avaliação do Guia, figura a adequação da estrutura editorial e do projeto gráfico, e consta ainda a prerrogativa de que as obras devessem reconhecer as marcas identitárias dos diversos alunos brasileiros, tais como gênero, raça e classe social, entre outras, além da diversidade de contextos de ensino e aprendizagem do Brasil, prevendo a diversidade do público alvo ao qual ele se destina. Consta ainda que:

0 livro didático influencia a formação das identidades dos indivíduos, que são construídas e reconstruídas a partir da relação com 0 outro. Portanto, é fundamental que os livros contribuam para a desnaturalização das desigualdades e promovam o respeito às diferenças. Em síntese, o livro precisa contribuir para a formação de cidadãos críticos e reflexivos, desprovidos de preconceitos, capazes de respeitar a si mesmos e a outros, a sua própria cultura e as dos outros, partindo de experiências críticas e reflexivas ${ }^{2}$ (BRASIL. 1998: p. 12).

Feita a seleção das coleções de livros didáticos, o próximo passo consistiu na observação das imagens presentes nesses exemplares, classificando-as a partir de uma das três classes ${ }^{3}$ : 1. 0 outro; 2. modos de posicionamento em relação ao outro e 3. gradações entre xenofobia e xenofilia.

Cada uma dessas categorias, por sua vez, subdivide-se para dar conta de abarcar os múltiplos modos de elas se apresentarem ou se representarem. A primeira delas se subdivide em: a) visitante ou imigrante; b) originário de país central ou periférico; c) rico ou pobre;

d) branco ou não; e) adulto ou não; f) masculino ou feminino e g) integrado nas relações de trabalho ou não. A segunda se subdivide em:
a) modos de posicionamento por contraste;
b) por oposição, por heterogeneidade;
c) por hierarquia; d) por dominação;
e) por subordinaçãa; f) por justaposição;
g) por simetria; h) por equivalência e
i) por igualdade. A terceira se divide em:

a) denigração; b) hostilidade; c) temor;

d) suspeita; e) defensividade; f) segregacionismo;

g) tolerância; h) solidariedade; i) cordialidade;

j) hospitalidade; k) admiração.

Disponível em: $<$ http://portal.mec.gov.br/index.php?option=com_content\&view=article\&id=12389\&ltemid=1129>.

BRASIL, Parâmetros Curriculares Nacionais: terceiro e quarto ciclos do Ensino Fundamental: Língua Estrangeira. Brasília: MEC, 1998.

Essas categorias foram as adotadas por Lúcia Santaella, no curso Teorias Culturalistas de Comunicação, ministrado no Programa de Comunicação e Semiótica, na PUC/SP, em 2008. 
Pois bem, foi a partir dessas estratégias metodológicas que pudemos exercitar o olhar para vislumbrar o outro que se apresentava nos livros didáticos. Neste artigo, apresentamos os resultados da pesquisa. Principiamos pela imagem. Sua presença no cotidiano impõe novos hábitos de ler o mundo e, sob o ponto de vista de Durand (2004) e Maffesoli (1996), apresentamos um olhar para a imagem despido da tradicional resiliência da elite intelectual acerca de seu papel e significância. Martín-Barbero (2014) e Rancière (2012) contribuem para que esse olhar se firme. Em seguida, apresentamos o conceito de alteridade a partir dos estudos de Kristeva (1994) e Todorov (2010) e, por fim, resultados das análises das representações visuais ancorados por Giddens (1993), para tratar a questão do gênero na contemporaneidade; Sodré (1999), sobre a questão da identidade do negro e sobre a questão do "branqueamento" promovido pela mídia; Da Matta (1994; 1997), para nos sustentar nas reflexões acerca da cultura e da identidade nacional, entre outros.

\section{A imagem como polo de agregação}

Negada por muito tempo, a imagem invade 0 mundo contemporâneo e se prolifera. Concluise que esse desprezo teve fim? Durand (2004) e Maffesoli (1996), seguidos de Rancière (2012) e Martín-Barbero (2014), contribuem para estas reflexões iniciais.

Afirma Durand (2004, p. 5) que todo o progresso das técnicas de reprodução por imagens, como a fotografia, o vídeo, as "imagens sintéticas", bem como os meios de transmissão não permitiram ao século XX acompanhar a construção de uma "civilização da imagem". 0 reino da "galáxia de Gutemberg" (expressão de Mc Luhan) ou da supremacia da imprensa e da comunicação escrita não se abalou, segundo o autor (2004, p. 5-6), diante da enorme riqueza de sintaxes, retóricas e todos os processos de raciocínio envolvendo a imagem mental - perceptiva, das lembranças, das ilusões etc. - e das icônicas - figurativo pintado, desenhado, esculpido e fotografado. Essas imagens permitiram recenseamentos e classificações que tornaram possíveis estudos de processos de produção, transmissão e recepção para as imagens passadas, possíveis, produzidas e a serem produzidas.

Ainda na esteira de Durand (2004, p. 31-2), na confluência do iconoclasmo ocidental e do papel "cognitivo" da imagem, ocorre a "revolução do vídeo", que tem início com a descoberta da fotografia. Depois dela, vem a animação da imagem produzida quimicamente, a transmissão instantânea das imagens e filmes a distância como fruto da aplicação das telecomunicações; em seguida, as imagens na televisão e, por fim, a descoberta da onda eletromagnética, que possibilitou a "explosão da comunicação" e a difusão de imagens. A onipresença da imagem tem um "efeito perverso", segundo o autor; no entanto, este não foi previsto e nem mesmo considerado. "Embora a pesquisa triunfal decorrente do positivismo tenha se apaixonado pelos meios 
técnicos (óticos, físico-químicos, eletromagnéticos etc.) da produção, reprodução e transmissão de imagens, ela continuou ignorando o produto de suas descobertas" (DURAND, 2004, p. 33).

Não ocorreu, em paralelo, uma "explosão do imaginário", pois, segundo o mesmo autor, o ocidente que se acredita "vacinado por seu iconoclasmo endêmico" continua menosprezando a imagem, delimitando-a ao campo da distração.

Todavia, as difusoras de imagens - digamos a "mídia" - encontram-se onipresentes em todos os níveis de representação e da psique do homem ocidental ou ocidentalizado. A imagem mediática está presente desde o berço até 0 túmulo, ditando as intenções de produtores anônimos ou ocultos: no despertar pedagógico da criança, nas escolhas tipológicas (a aparência) de cada pessoa, até nos usos e costumes públicos ou privados, às vezes como 'informação', às vezes velando a ideologia de uma 'propaganda', e noutras escondendo-se atrás de uma 'publicidade' sedutora (...). A importância da 'manipulação icônica' (relativa à imagem) todavia não inquieta. (DURAND, 2004, p. 34)

Também para Maffesoli (1996), as imagens

podem ser agregadas aos fatores que tecem as relações que configuram a sociedade contemporânea. Trata-se de imagens que brincam, num jogo irônico, com aspectos do cotidiano e que permeiam todas as relações, quer por se deixarem ver ou se apresentarem - as representações visuais, de modo geral -, quer por se incorporarem, em algum aspecto, ao imaginário das pessoas. Isso não as torna desprezíveis, pois "a imagem é expressão do vitalismo e enraíza-se num substrato natural. Por isso, ela é ecológica por construção. Isto é, estabelece correspondências (sociais, naturais) e favorece interações" (MAFFESOLI, 1996, p. 135).

Para além do entretenimento, ou da possibilidade de contribuir no jogo de relações que estruturam a nossa sociedade, ou do potencial da imagem para agregar pessoas, encontramos a proposta de Rancière, sobre a relação entre imagem e política, o que, em certa medida, também especifica uma maneira de agregação. Conforme Rancière, a imagem é "um elemento num dispositivo que cria certo senso de realidade, certo senso comum". Nas palavras de Rancière (2012, p. 99), o senso comum caracteriza uma "comunidade de dados sensíveis":

[...] coisas cuja visibilidade considera-se partiIhável por todos, modos de percepção dessas coisas e significados também partilháveis que Ihes são conferidos. É também a forma de convívio que liga indivíduos ou grupos com base nessa comunidade primeira entre palavras e coisas. 0 sistema de informação é um "senso comum" desse tipo: um dispositivo espaço-tempo dentro do qual palavras e formas visíveis são reunidas em dados comuns, em maneiras comuns de perceber, de ser afetado e de dar sentido.

Sendo assim, a imagem pode ser pertinente para criticar a realidade, caso ela rompa com o senso comum construído por um dispositivo. No entanto, conforme Ranciére (2012, p. 99), não se trata de "opor a realidade a suas aparências", mas de "construir outras realidades, outras formas de senso comum, ou seja, outros dispositivos espaçotemporais, outras comunidades de palavras e coisas, formas e significados". 
0 livro didático (impresso), em certa medida, contribui para estabelecer um senso comum sobre a relação palavra/imagem, dado pela preponderância da palavra em relação à imagem (desenhos, gravuras, fotografias, diagramas, gráficos e outras modalidades de representações visuais).

Sob a ótica de Martín-Barbero (2014, p. 104), voltada para a comunicação na educação, temos que, embora a intelectualidade tenha mantido "um permanente receio sobre 0 mundo das imagens, ao mesmo tempo em que a 'cidade das letras' continua procurando, a todo momento, controlar a imagem, confinando-a de forma maniqueísta ao campo da arte ou ao mundo da aparência enganosa e dos resíduos mágicos", a imagem avança, retorna com força, adentra 0 ambiente educacional sorrateiramente - e se instala, introduzindo um novo estatuto cognitivo que desconcerta tradicionais formas de pensar o conhecimento.

0 que se vislumbra nesse cenário é que 0 velho medo da imagem reaparece travestido de espetacularização legitimada pelo prestígio intelectual, o que a afasta da escola. 0 que fica na esfera do não dito é que 0 mundo audiovisual desafia a escola em níveis mais específicos: "o da 'sociedade da informação' e 0 dos novos espaços e formas de socialização" (MARTÍN-BARBERO, 2014, p. 65); o contato permitido com os meios e com a tecnologia não como estratégia de conhecimento, mas apenas pelo uso instrumental. A escola esgueira-se, dessa forma, da emergência de um ecossistema educativo - requisitado pela revolução tecnológica - que se constitui não apenas de novas máquinas ou meios, mas de novas linguagens, escritas e saberes, conformado "pela hegemonia da experiência audiovisual pela tipográfica e a reintegração da imagem ao campo da produção de conhecimentos" (MARTíNBARBER0, 2014, p. 66).

0 autor relativiza a polarização que apresenta, de um lado, o livro atrelado à razão; de outro, a imagem voltada para as projeções irracionais, partícipes do terreno da simulação e das manipulações consumistas. Para Martín-Barbero, o livro pertence à primeira alfabetização, enquanto as outras escrituras - do videogame ao videoclipe, do grafite ao hipertexto - correspondem à segunda alfabetização. 0 que decorre daí é que a visibilidade da imagem dá lugar à sua legibilidade. Esses novos modos de ler se fazem imprescindíveis, sobretudo frente à urgência de se oferecer ao aluno/cidadão o conhecimento do sentido social da vida e a vivência da democracia.

1Nessa pesquisa, vamos colher representações visuais do "outro" em livros didáticos. Sobre 0 que estamos entendendo por alteridade e sobre que "outros" foram abordados nas análises, discorremos a seguir.

\section{Sobre a questão da alteridade}

Tomamos de empréstimo o estrangeiro da concepção de Kristeva e Todorov - aquele que não 
tem a cidadania do país que habita - para depois ampliá-la, alcançando o outro, o diferente no seio de um conjunto, por definição, formado pela exclusão dos semelhantes.

Nesse contexto, segundo Kristeva (1994), o estrangeiro deseja ser reconhecido, reconhece-se diferente e impõe, mesmo que involuntariamente, essa diferença. Ele lança à identidade do grupo, tanto quanto à sua própria, 0 desafio da convivência, e as relações podem ser permeadas por violência, intrusão, sofrimento, fragilidade, humildade, arrogância, dominação.

Diferenças de sexo, idade, profissão e credo contribuem para a formação do estado do estrangeiro, acrescenta a mesma autora. 0 grupo do qual o estrangeiro não participa, provavelmente, é um grupo social formado em torno de algum tipo de poder político. " 0 estrangeiro pode ser situado como benéfico ou maléfico para esse grupo social e, por esta razão, ele deve ser assimilado ou rejeitado" (KRISTEVA, 1994, p.101).

Assim, do ponto de vista político, o estrangeiro "assinala os limites dos Estados-nações e da consciência política nacional, ao ponto de se considerar como normal que existam estrangeiros, isto é, pessoas que não têm os mesmos direitos que nós" (KRISTEVA, 1994, p. 108).

Para concluir a noção de estrangeiro à luz de Kristeva, deparamo-nos com a inserção do inconsciente freudiano nessa construção.
Com Freud, "0 estranho, o aflitivo, insinua-se na quietude da própria razão e, sem se limitar à loucura, à beleza, ou à fé, nem à etnia ou à raça, irriga o nosso próprio ser-de-palavra, estrangeirado por outras lógicas, incluindo a heterogeneidade da biologia" (KRISTEVA, 1994, p.177). Com base nessa afirmação, é possível que o indivíduo saiba que ele é um estrangeiro de si mesmo e, a partir desse único ponto, é que ele tenta viver com os outros. Nesse sentido, vêm as palavras de Kristeva (1994, p. 9):

Estranhamente, o estrangeiro habita em nós: ele é face oculta da nossa identidade, o espaço que arruína a nossa morada, o tempo em que afundam 0 entendimento e a simpatia. Por reconhecê-lo em nós, poupamo-nos de ter que detestá-lo em si mesmo. Sintoma que torna o "nós" precisamente problemático, talvez impossível, o estrangeiro começa quando surge a consciência de minha diferença e termina quando nos reconhecemos todos estrangeiros, rebeldes aos vínculos e às comunidades.

Assim, "uma comunidade paradoxal está surgindo, feita de estrangeiros que se aceitam na medida em que eles próprios se reconhecem estrangeiros" (KRISTEVA, 1994, p. 205). Nela, o fato de viver com 0 outro envolve não só a "aptidão em aceitar 0 outro, mas de estar em seu lugar - 0 que equivale a pensar sobre si e se fazer outro para si mesmo" (KRISTEVA, 1994, p. 21).

Reflexões sobre a problemática do outro, do estrangeiro, sob a perspectiva de Todorov (2010), têm como ponto de partida a colonização da América pelos espanhóis. 0 autor considera 
este um dos encontros mais surpreendentes da história mundial, pois mostra 0 embate do homem europeu com um continente cuja existência era desconhecida, bem como os homens que ali habitavam.

De acordo com Todorov (2010), um indivíduo pode perceber o outro em si mesmo e, quando faz isso, nota que 0 outro que está em si é diferente de tudo o que não é si mesmo. Sendo assim, o eu é um outro e cada um dos outros é um eu também. Vejamos a explicação do embate do eu com o outro nas palavras de Todorov (2010, p. 3-4):

Posso conceber os outros como uma abstração, como uma instância da configuração psíquica de todo indivíduo, como o Outro, outro ou outrem em relação a mim. Ou então como um grupo social concreto ao qual nós não pertencemos. Este grupo, por sua vez, pode estar contido numa sociedade: as mulheres para os homens, os ricos para os pobres, os loucos para os "normais". Ou pode ser exterior a ela, uma outra sociedade que, dependendo do caso, será próxima ou longínqua: seres que em tudo se aproximam de nós, no plano cultural, moral e histórico, ou desconhecidos, estrangeiros cuja língua e costumes não compreendo, tão estrangeiros que chego a hesitar em reconhecer que pertencemos a uma mesma espécie.

Das reflexões de Todorov (2010), vêm os modos de relacionamento com o outro, que podem dar conta da problemática da alteridade, distintos em três eixos, como a seguir:

Primeiramente, um julgamento de valor: 0 outro é bom ou mau, gosto dele ou não gosto dele, ou, como se dizia na época, me é igual ou me é inferior. Há, em segundo lugar, a ação de apro- ximação ou distanciamento em relação ao outro: adoto valores do outro, identifico-me a ele; ou então assimilo o outro, impondo-lhe minha própria imagem; entre a submissão ao outro e a submissão do outro há ainda um terceiro termo, que é a neutralidade, ou indiferença. Em terceiro lugar, conheço ou ignoro a identidade do outro. (TODOROV, 2010, p. 269)

0s "outros" que se fizeram representar nos livros didáticos pesquisados tipificam relações de gênero, questões étnicas e a questão da identidade nacional. 0 tópico a seguir traz recortes de resultados da pesquisa. Exemplificamos com imagens de algumas das coleções pesquisadas, imagens anteriormente analisadas a partir do instrumental semiótico peirceano.

\section{Resultados...}

Nas coleções de Português, a abordagem da alteridade deu-se sob dois aspectos: gênero e etnia. 0 entendimento de gênero que permeia essas reflexões destaca-se pela ambivalência. De um lado, acentua as fendas entre masculino e feminino, ampliando as diferenças. Essa concepção binária, que sustenta 0 ideário da sociedade machista, polariza as relações e reforça a ideia da oposição entre um e outro dominado, na qual o primeiro elemento exerce a superioridade; o outro, em sendo derivado do primeiro, se submete. De outro lado, está a concepção de gênero ligada à questão das identidades moventes e plurais tratada pelos estudos culturais referentes à pós-modernidade. Tal instabilidade é decorrente da mudança estrutural que, no 
fim do século XX, segundo Hall (2006, p. 9), fragmentou as "paisagens culturais de classe, gênero, sexualidade, etnia, raça e nacionalidade, que, no passado, nos tinham fornecido sólidas localizações como indivíduos sociais", provocando no sujeito a incerteza da própria identidade ou a "descentração do sujeito". Nessa perspectiva, dissolvem-se os papéis fixos e, com eles, a ideia de um modelo fechado de masculinidade e feminilidade.

A identidade de gênero ou a sexual está sempre se constituindo, são instáveis e passíveis de transformação. Essas reflexões deram-se na esteira de Hall (2006), principalmente, sobre a construção da identidade social na pósmodernidade; com Giddens (1993) e Louro (1997), tratamos da relação masculino/feminino. Afinal, qual dessas instâncias o livro didático reproduz ou produz?

0 levantamento das imagens, num primeiro momento, trouxe como resultado a proeminência do universo masculino tanto na quantidade de figuras deste gênero por página, no número de autores dos textos que compunham os livros e no de seus protagonistas. Submetidas essas imagens a categorias que verificavam os modos de constituição do feminino/masculino no espaço público, bem como a postura diante do outro, mais uma vez vislumbramos a manutenção das desigualdades pelo predomínio de estereótipos. A menina ainda é a que brinca de casinha, de boneca, e a mulher que se transforma em dona de casa ou professora; o menino brinca de bola, carrinho, quer ser jogador de futebol, médico ou dentista.

A homossexualidade é sugerida poucas vezes. Duas circunstâncias nos pareceram significativas: numa delas, predomina um tratamento agressivo que reforça 0 ideal da "macheza" (FIG.1), faz apologia à brutalidade, acentua as diferenças e, consequentemente, a separação de gêneros. Noutra, o menino que brinca com menina (FIG. 2) ou o que brinca com coisas de menina (FIG. 3) são tratados com leveza, abrindo espaço para que a diversidade possa ser contemplada e brechas sejam abertas para a dissuasão da rigidez do estabelecido.

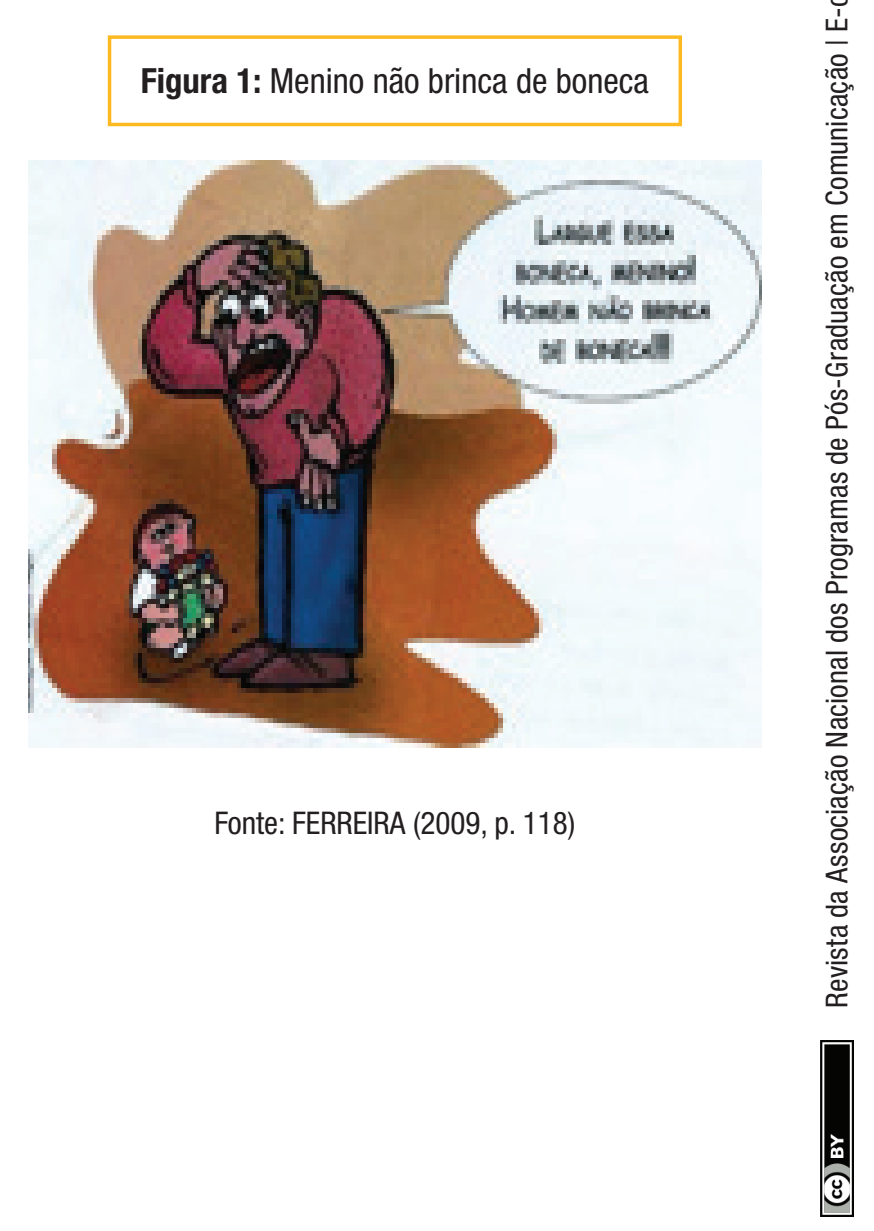




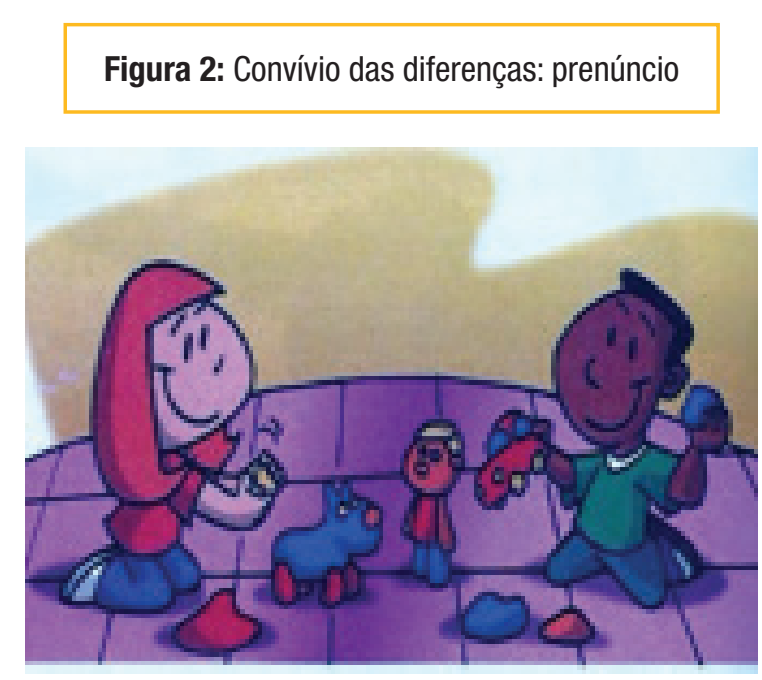

Fonte: CARVALHO; ANSON (2008, p.74)

Figura 3: 0 convívio das diferenças

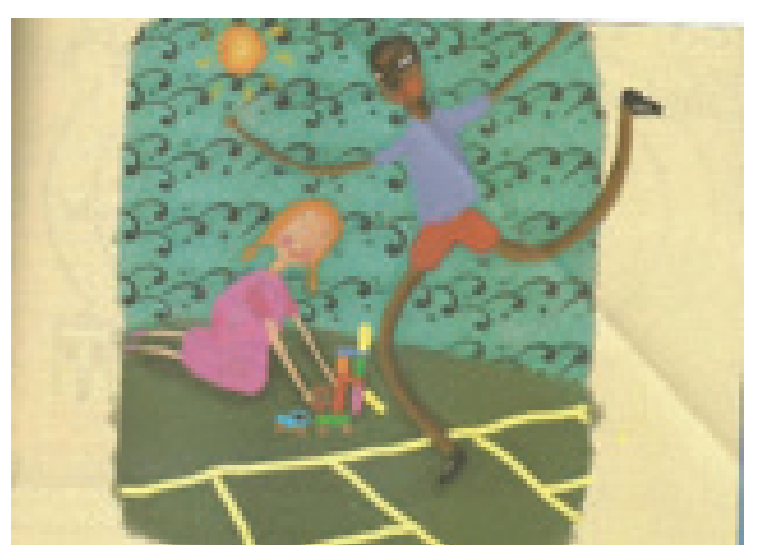

Fonte: FERREIRA (2009, p.135)

Ainda nas coleções de Português, pudemos pesquisar o modo como o negro era representado ou, mais precisamente, a mulher negra, a partir do viés do cabelo enquanto marca simbólica e identitária. Ancoradas pelas ideias de Sodré (1999) sobre o tema, interessava-nos verificar se 0 material didático fazia ecoar 0 discurso reprodutor da identidade do homem de cor regida pelo "branqueamento" produzido pelas mídias ou, o contrário, contribuía para preservar a herança cultural africana.
Sodré (1999) sustenta que representações

identitárias do negro veiculadas pelo discurso hegemônico da sociedade brasileira reforçamlhe 0 caráter primitivo, exótico; acentuam as diferenças em virtude dos traços fenotípicos. À ideia de mestiçagem ou amorenamento subjaz a noção de uma raça apta a desfazer a distância entre a pigmentação escura e 0 paradigma brancoeuropeu, capaz de representar a unidade da raça na materialização de uma "terceira raça". Sodré, contudo, avisa:

Falar-se de raça só é admissível como noção cul-
turalmente (e jamais biologicamente) marcada,
donde a possibilidade da 'relação racial', isto é,
aquela caracterizada por dissimetria nas relações
hierárquicas e simbólicas entre os seres huma-
nos em virtude de diferenças fenotípicas (S0-
DRÉ.1999, p. 194).

0 cabelo destaca-se dentre os traços fenotípicos e, para Sodré, a obsessão contemporânea com 0 cabelo explica-se pelo fato de que 0 atual discurso midiático sobre o negro é mais estético do que político, doutrinário ou ético. Essa forma de construir um imaginário forjado numa identificação com padrões idealizados esconde o fato de que a diferença é sempre histórica e produzida numa relação com indivíduos e grupos hegemônicos. É sutil e astuciosa a maneira como esses padrões são impostos sem a presença de afrontamentos. 0 sujeito de cor se submete ao corpo ideal oferecido como modelo pela mídia. Investido desse ideário, o corpo-mídia do negro tornado performático, reveste-se de uma fantasia étnica que mascara a desigualdade social. 
Encontramos, nos livros consultados, imagens que apresentavam 0 cabelo em diferentes nuances: 0 cabelo coberto que simbolizava a exclusão ancorada pela forte referência à escravidão (FIG.4); 0 cabelo crespo que valorizava 0 biótipo afro (FIG. 5) e 0 cabelo ondulado que "passava a limpo" a negritude (FIG. 6), fazendo vir à tona o corpo-mídia.

\section{Figura 4: Afrodescendência em cena}

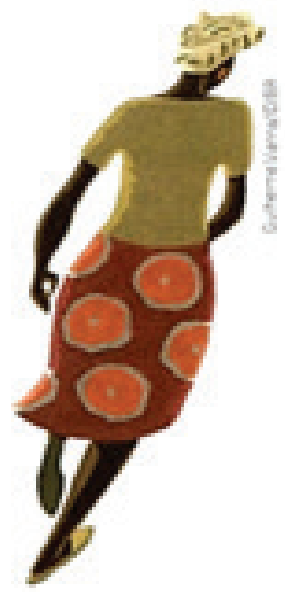

Fonte: MARCHETTI (2011, p. 182)

Figura 5: 0 exótico em cena

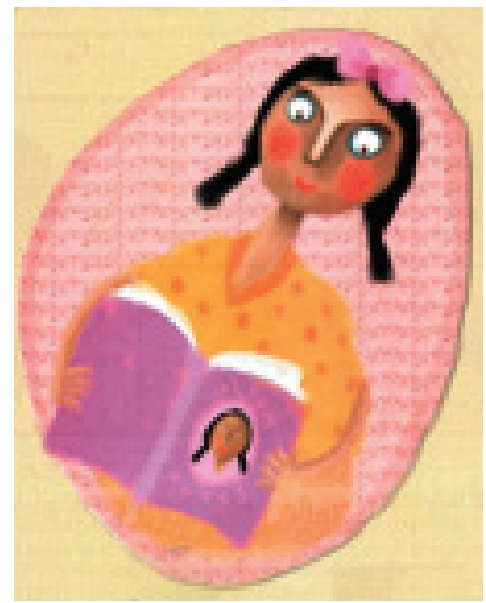

Fonte: FERREIRA (2009, p. 9)
Figura 6: A mulata em cena

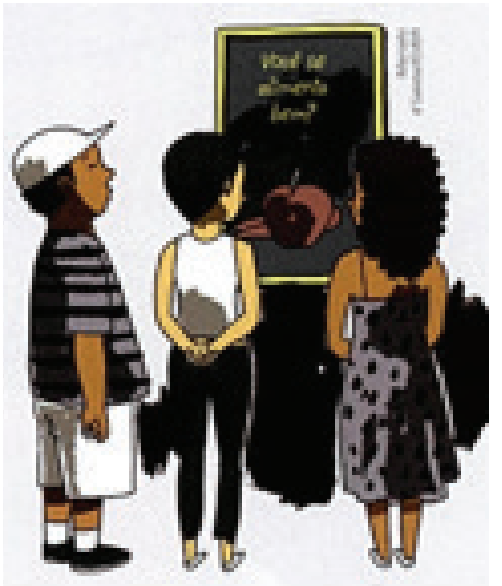

Fonte: TERRA; CAVALLETE (2009, p. 57)

A faceta que mais representações visuais incorporou foi a da categoria relativa à preservação da herança cultural africana. Sob esse prisma, pensamos que, talvez, este olhar dirigido à exterioridade da mulher afrodescendente como o "outro" revele um tratamento respeitoso das diferenças, que contribui para que os alunos/aprendizes possam vivenciar a experiência da alteridade.

0s livros de História, com recorte na História do Brasil, tiveram como foco o modo como a cultura e a identidade nacional se apresentavam nas representações visuais. Dentre as 904 imagens classificadas nas várias modalidades, utilizadas como padrão para todos os livros analisados nesta fase reproduções de fotografias, de obras de arte, de produtos midiáticos e ilustrações - nas quais predominavam momentos bem pontuais da História do Brasil, as imagens mais representativas consistiram em três painéis. 
0 primeiro painel (FIG. 7) apresenta uma versão da cultura nacional mergulhada no folclore característico dos vários estados: o Festival de Folclore de Parintins/AM; o Maracatu de Olinda/ PE; a Festa Junina de Campina Grande/PB; Festa da Cavalhada de Pirenópolis/GO; Festa da Uva em Bento Gonçalves/RS; Oktoberfest em Blumenau/ SC; Escola de Samba no Rio de Janeiro/RJ e o Bumba meu boi em São Luís do Maranhão. Desta forma, costumes, arte e religião definidos pela localização geográfica se faziam ver.

No segundo painel (FIG. 8), um outro Brasil se apresenta: uma versão às avessas do país em festa que traz à baila problemas urbanos, tais como falta de moradias, aumento de favelas, saneamento básico precário, congestionamento de trânsito, poluição, acúmulo de lixo, carência de serviços públicos de saúde, educação, transporte e 0 aumento da violência: enfim, traços reveladores do que se tenta ocultar dos olhos de outrem. A outra face da moeda... Corresponde ao 'brasil' (minúsculo) que Roberto DaMatta (1994) denominou como sendo um dos polos do modo de construção da identidade brasileira, o que pode ser medido por dados estatísticos que nos levam a constatar que não é o país que gostaríamos que fosse.

0 terceiro (FIG. 9), contudo, faz a síntese dos dois "brasis": em torno do Cristo Redentor, são justapostos cenários de miséria e carnaval. Celebra-se a manutenção da ordem social, com suas diferenças e gradações, seus poderes e hierarquias, tendo o sagrado como ponto fulcral. 0 apagamento das diferenças inviabiliza um tratamento mais crítico, sobretudo em se considerando tratar de livros didáticos que devem notabilizar-se pelo compromisso com um tratamento mais reflexivo da história.

Figura 7: A cara do Brasil I

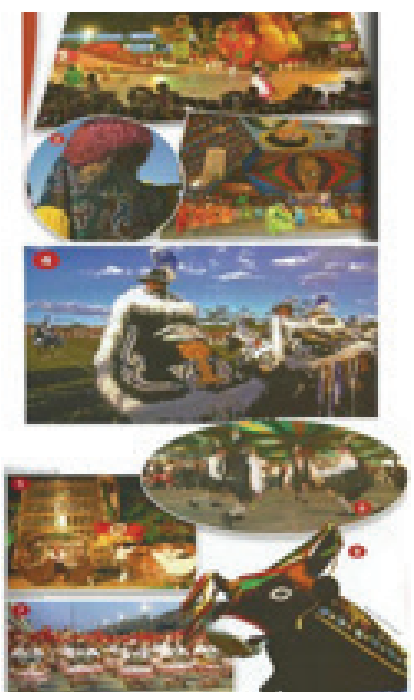

Fonte: BOULOS (2012, p. 10-1)

Figura 8: A cara do Brasil II

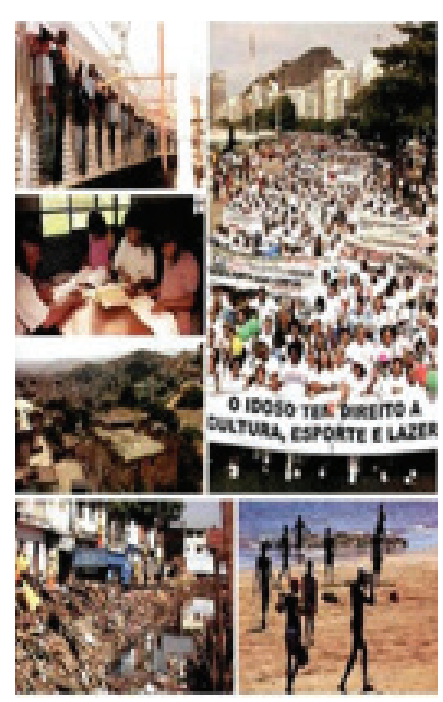

Fonte: RODRIGUES (2009, p. 293) 
Figura 9: Que país é este?

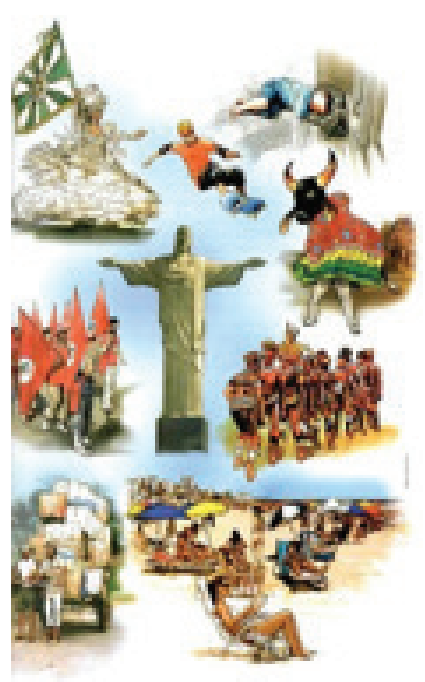

Fonte: RODRIGUES (2009, p. 283)

0 índio como o "outro" foi o próximo a ser pesquisado nas representações visuais das coleções de História e Geografia. 0 propósito era 0 de verificar se a complexidade cultural desses povos estava impressa nas imagens e se essas representações contribuíam para a construção ou desconstrução do olhar do colonizador lançado sobre os povos originários, na perspectiva de Jameson (2006). Uma teoria da visão, conforme este autor (2006, p. 129), depende "necessariamente da elaboração histórica de uma cultura social e de uma experiência social da visão, que depois teoriza”. A partir disso, Jameson propõe três modalidades de olhar: 0 colonial, 0 burocrático e o pós-moderno. 0 primeiro olhar, pertinente ao contexto deste artigo, construiu-se com a colonização e, portanto, a Europa tornou-se o lugar de onde se vê o colonizado. Trata-se de um olhar assimétrico, e a visibilidade é percebida pelo fato e pela opressão de ser visto, que continua na ausência do colonizador. Este olhar, do ponto de vista geométrico, corresponde ao olhar panóptico, que focaliza o objeto e lança-lhe luzes, para que possa ser classificado, dissecado, distorcido. Não há encontro de olhares, não há diálogos.

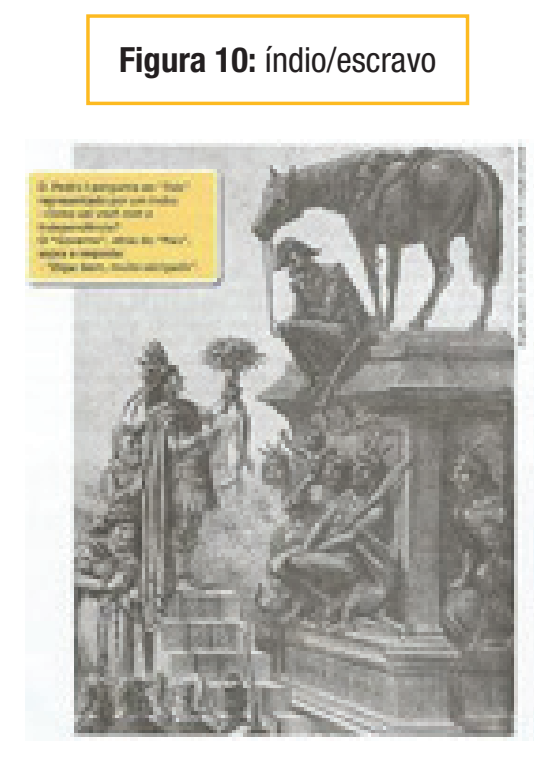

Fonte: BOULOS (2012, p.196)

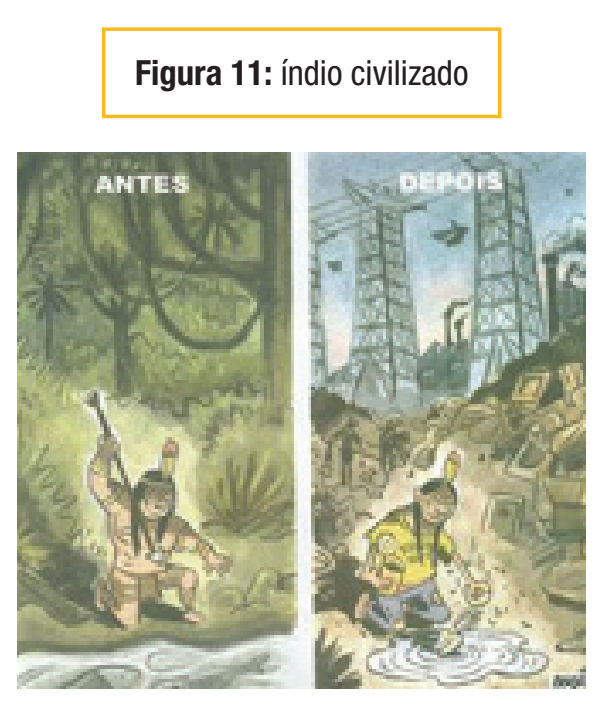

Fonte: PELEGRINI (2009, p. 19) 
Figura 12: a justiça de cocar

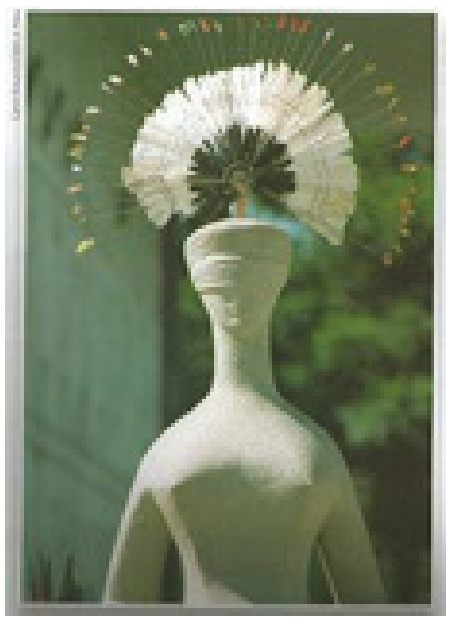

Fonte: BOULOS (2012, p. 301)

Nas coleções de Geografia, encontramos 2870 representações visuais distribuídas em 1777 páginas, com uma média de 1,6 figuras por página do livro. As coleções de História contabilizaram 4185 páginas, que contaram com 5583 representações visuais, com uma média de 1,3 representações visuais por página, portanto. Encontramos 67 representações visuais em que os povos originários estão presentes, o que corresponde a $0,8 \%$ do total de imagens.

Para tentar dar conta das especificidades dessas representações visuais, optamos por construir as seguintes classes nas quais se distribuem as 67 imagens: 1. Cotidiano e Cultura (46\%); 2. Colonização e outros períodos da História (36\%); 3. Lendas e mitos dos povos originários (3\%); 4.0 índio para além das fronteiras de suas terras ou aldeias (9\%) e 5. Representação Visual/Denúncia (6\%).
Apenas três (duas charges, uma foto jornalística), das 67 imagens coletadas, rompem com a estereotipia do exótico, do "selvagem" feliz com a liberdade e em harmonia com a natureza, olhar tão afeito ao colonizador. Numa delas, denuncia-se a escravização do índio no tempo do Brasil colônia, tempo em que 0 segregacionismo imperava (FIG.10). Noutra, denuncia-se a dificuldade de se viver em harmonia com a natureza em meio à degradação do meio ambiente (FIG. 11). Na terceira, a estátua da deusa da Justiça instalada em Brasília, em frente ao Palácio da Justiça, tem na cabeça um cocar (FIG. 12).

Um pedido de inserção pode ser interpretado nesse clamor. Ainda que com timidez, esses $0,2 \%$ podem abrir brechas para se pensar sobre aspectos da complexidade cultural e ética dos povos originários; contudo, não caminham no sentido de desconstruir o olhar do colonizador nos educandos, dando-lhe subsídios para a construção de uma visão mais crítica sobre os povos originários.

A coleção de língua estrangeira examinada trouxe 1497 imagens em 712 páginas. A base para a classificação das imagens foi similar às utilizadas nas outras coleções: as que favoreciam o olhar 0 "outro". De modo geral, privilegiouse 0 grupo, 0 coletivo e, nele, a diversidade de etnias, nacionalidades. A língua espanhola era 0 ponto de confluência entre elas. A bandeira, o povo, o folclore, a arte latino-americana, seus mitos, personalidades e artistas eram elementos 
recorrentes nas imagens, o que pode nos levar a interpretar 0 acolhimento do outro, 0 respeito pela sua história. As imagens sugerem uma relação cordial entre povos de idioma comum, mas culturas diversas.

\section{Considerações Finais}

De modo geral, pudemos constatar o número excessivo de imagens desprovidas de qualidade ou de função. No tocante à questão que gerou esta pesquisa, é possível afirmar, em linhas gerais, que há preocupação com a diversidade, principalmente no que se refere aos aspectos étnicos.

Na relação de gênero, embora as imagens reforçassem estereótipos, vislumbrou-se uma tímida manifestação de aceitação do outro ao se verificar, na materialidade de algumas imagens, 0 esboço de uma reformulação de sentidos. Assim, a separação de gêneros é atenuada e novos caminhos são apontados.

No que diz respeito à questão étnica, o tratamento dado à mulher negra, a partir do viés do cabelo enquanto marca simbólica e identitária, não protagonizou o discurso reprodutor da identidade da mulher negra regida pelo "branqueamento" produzido pelas outras mídias. Ao contrário, o que se descortinou foi o discurso de preservação da herança cultural africana. Nesse caso, as representações visuais vão ao encontro da proposta de Rancière, ao romperem com o senso comum.
0 mesmo não se dá nos dois próximos casos, com representações do índio e imagens do Brasil. 0 índio revelou-se nas imagens a partir das mesmas convenções. Também nesse caso, as representações visuais não denigrem ou segregam o índio, apenas o tomam a partir dos estereótipos característicos do olhar do colonizador, sem considerar sua complexidade cultural. A imagem do Brasil como território de muitos 'outros' revela-se nos livros de História, à luz de DaMatta, enquanto país de "rotinas e ritos, trabalho e festa, corpo e alma, coisas dos homens e assuntos dos deuses", uma visão que ameniza as diferenças ou as encobre sob as vestes da crença divina. A identidade manifesta contrasta com a ideia contemporânea em que as identidades sociais, culturais e sexuais são fluidas.

Uma visão mais voltada à união dos povos pela mediação da língua faz-se ver na coleção de língua estrangeira. A diversidade de povos, culturas, mitos e arte estão presentes nas representações visuais. Também nas coleções de Matemática e Ciências, fotografias e ilustrações primam por documentar, registrar as diferenças de idade, gênero e etnia, entre outras, sempre numa ambiência de agregação, de convivência harmoniosa com o outro.

Por fim, as análises realizadas mostram que as representações visuais, de modo geral, tanto as que apresentam crianças como adultos quer sejam fotografias ou ilustrações -, de um lado, primam por documentar, registrar 
as diferenças étnicas; de outro, agregam os diferentes, sugerindo receptividade, acolhida ao outro, nos diversos ambientes apresentados nos livros didáticos. Não há indícios que levem 0 intérprete a conjeturar alguma modalidade de xenofobia. No entanto, o excesso de imagens e de situações em que as diferenças se fazem ver pode provocar efeito contrário ao pretendido. Elas podem não ser notadas ou se mostrarem ao intérprete como apelativas.

É fundamental que os livros didáticos promovam 0 respeito às diferenças para contribuir para a formação de cidadãos críticos, sem preconceitos e capazes de respeitar os outros, bem como a si próprios. Neste sentido, vale reforçar a importância da educação do olhar para as representações visuais, sobretudo porque a imagem guarda um potencial de sentidos inscrito em seus aspectos qualitativos, tais como formas, cores e texturas; em seus aspectos existenciais capazes de reportar 0 intérprete ao objeto representado e, finalmente, inscrito nos aspectos simbólicos que as impregnam. Uma imagem clama por um olhar que possa penetrar estas camadas de sentido...

Daí a necessidade de aprendizagem de estratégias metodológicas para análise de imagens.

Os resultados nos levam a enfatizar, em primeiro lugar, a necessidade de zelar pela pertinência da ilustração no livro didático, de modo que ela seja coerente com a linguagem da disciplina escolar, a fim de, assim, contribuir para o desencadear de processos cognitivos. Em segundo, caso seja mero eco da linguagem verbal ou prime pela redundância, a ilustração pode vir em menor quantidade; contudo, considerando-se a alteridade, é preciso não reforçar estereótipos e sugerir, ainda que de modo sutil, a convivência com as diferenças.

\section{Referências}

BOULOS, Jr. História, sociedade \& cidadania. $9^{\circ}$ ano. São Paulo: FTD, 2012.

BRASIL, Parâmetros Curriculares Nacionais: terceiro e quarto ciclos do Ensino Fundamental: Língua Estrangeira. Brasília: MEC, 1998.

CAMPOS, E. (et. Al.) Viva Português. São Paulo: Ática, 2012, v.7, 9 .

CARVALHO, R; ANSON, V. A grande aventura: língua portuguesa. São Paulo: FTD - Coleção A grande aventura - 2008 .

PEIRCE, C.S.; HARTSHORNE, C.; WEISS, P. 1994 [1959]. The collected papers of Charles Sanders Peirce. Cambridge, Harvard University Press. [CD-ROM].

DA MATTA, R. 0 que faz o brasil, Brasil? Rio de Janeiro: Rocco, 1994.

. Carnavais, malandros e heróis: para uma sociologia do dilema brasileiro. Rio de Janeiro: Rocco, 1997.

DURAND, G. 0 imaginário: ensaio acerca das ciências e da filosofia da imagem. Tradução de Renee Eve Levie. $3^{\mathrm{a}}$ ed. Rio de Janeiro: Difel, 2004.

FERREIRA, G. (et al.) (2009). Trabalhando com a linguagem. São Paulo: Quinteto Editorial, 2009, v. 7.

GIDDENS, A. A transformação da intimidade: sexualidade, amor\& erotismo nas sociedades modernas. São Paulo: Editora da universidade Estadual Paulista, 1996. 
GUIA DE LIVROS DIDÁTICOS: PNLD 2011 - Brasília: Ministério da Educação, Secretaria de Educação Básica, 2010 (para todas as disciplinas escolares). Disponível em:

$<$ http://portal.mec.gov.br/index.php?option=com_cont ent\&view $=$ article\&id $=12389 \&$ Itemid $=1129>$.

JAMESON, F. Espaço e imagem: teorias do pósmoderno e outros ensaios. Rio de Janeiro: EUFRJ, 2006.

KRISTEVA, J. Estrangeiros para nós mesmos. Rio de Janeiro: Rocco, 1994.

LOUR0, G. L. (1997) Gênero, sexualidade, educação: uma perspectiva pós-estruturalista. Rio de Janeiro: Editora Vozes.

MAFFESOLI, M. (1996). A contemplação do mundo. Porto Alegre: Artes e ofícios.

MARCHETTI, G. (et. al.). Para viver juntos. São Paulo: Edições SM, 2011, v. 9.

MARTÍN-BARBERO, J. A comunicação na educação. São Paulo: Contexto, 2014.

PELEGRINI, M; DIAS, A. M.; GRINBERG, K. Vontade de saber História. São Paulo: FTD, 2009.

PENTEAD0, A. E. Arruda (et. al.) Para viver juntos. São Paulo: Edições SM, 2011, v. 8.

RANCIÈRE, J. 0 espectador emancipado. São Paulo: Editora WMF Martins Fontes, 2012.

RODRIGUES, J. E. História em documento. $9^{\circ}$ ano. São Paulo: FTD, 2009.

SANTAELLA, L. Semiótica aplicada. São Paulo: Thomson, 2002. 186p.

SODRÉ, M. Claros e escuros: Identidade, povo e mídia no Brasil. Petrópolis, RJ: Vozes, 1999.

SOUZA, L. C. P. Reflexões sobre o livro como meio de comunicação: a crise da leitura ou a emergência de novos "modos de ler"? Descentramento do livro e da escola como eixos do saber. Revista de Estudo Universitários, REU, Sorocaba, SP, v. 41, n. 1, p. 127129, jun. 2015.

SOUZA, L. C. P; DRIGO, M. 0. Aspectos da interrelação Comunicação e Educação: o potencial de sentidos de representações visuais. Revista Brasileira de Ciências da Comunicação -INTERCOM. São Paulo, v. 36, n. 2, p. 291 - 312, Julho/Dezembro 2013.

Representações visuais da

mulher afrodescendente em livros didáticos. Revista Comunicação \& Educação. Ano XIX, n. 1, p. 51 - 58, Janeiro/junho de 2014.

Cultura e identidade nacional:

representações do Brasil em livros didáticos. C\&S

- São Bernardo do Campo, v. 36, n. 1, p. 255-278, jul./ dez. 2014.

Alteridade e os povos originários do Brasil: um estudo com representações visuais em livros didáticos. Conexão - Comunicação e Cultura, UCS, Caxias do Sul-v. 14, n. 28, p. 51-72, jul./dez. 2015.

TERRA, E.; CAVALLETE, F.T. Projeto Radix: raiz do conhecimento. São Paulo: Editora Scipione, 2009, v. 6, 7.

TODOROV, T. A conquista da América: a questão do outro. São Paulo: Martins Fontes, 1999. 


\section{Representations of the other: studies on images in textbooks}

\section{Abstract}

This article presents results of a research carried on under the support of FAPESP (São Paulo Foundation for Research Support), and whose context stems from the intersection between Communication and Education. Considering the fact that the textbook is among the media responsible for propagating messages involving otherness, whose focus is visual representations, our interest was to understand how the "other" was regarded and, to what extent, it favors the construction of ambiances that provide coexistence between differences, or otherwise.

Generally, the many "others" depicted in the selected material - Textbooks for the last levels of Elementary School - were positioned taking into account the nuances of proximity naturally provided when it comes to classify the way of being with the other. Ultimately, solidarity is the prevailing modality.

\section{Keywords}

Communication. Education. Otherness.

Visual representation. Textbooks.

\section{Representaciones del otro: estudio} con imagenes en libros escolares

\section{Resumen}

Este artículo presenta resultados de investigación emprendida bajo los auspicios de la FAPESP, cuyo contexto viene de la intersección entre Comunicación y Educación. Considerando el hecho de que el libro didáctico esté entre los medios responsables de propagar mensajes que involucran la alteridad, con foco en representaciones visuales, nos interesaba comprender el trato dado al otro y, en qué medida, ese favorece la construcción de ambientes que propician la construcción La coexistencia de las diferencias, o lo contrario. En general, los muchos otros que se presentaron en el material didáctico seleccionado - Libros Didácticos, para las series finales de la Enseñanza Fundamental de las disciplinas escolares -, se posicionaron con los matices de proximidad que la clasificación del modo de estar con el otro propician. La solidariedad es, en fin, la modalidad que prepondera.

\section{Palabras-clave}

Comunicación. Educación. Alteridad.

Representaciones visuales. Libros escolares. 


\section{Expediente}

A revista E-Compós é a publicação científica em formato eletrônico da Associação Nacional dos Programas de Pós-Graduação em Comunicação (Compós). Lançada em 2004, tem como principal finalidade difundir a produção acadêmica de pesquisadores da área de Comunicação, inseridos em instituições do Brasil e do exterior.

\section{E-COMPÓS I www.e-compos.org.br I E-ISSN 1808-2599}

Revista da Associação Nacional dos Programas de Pós-Graduação em Comunicação. Brasília, v.21, n.2, maio/ago. 2018. A identificação das edições, a partir de 2008, passa a ser volume anual com três números. Indexada por Latindex I www.latindex.unam.mx

\section{CONSELHO EDITORIAL}

Ada Cristina Machado Silveira, Universidade Federal de Santa Maria, Brasil Alda Cristina Silva da Costa, Universidade Federal do Pará, Brasil Alfredo Luiz Paes de Oliveira Suppia, Universidade Estadual de Campinas, Brasil Ana Regina Barros Rego Leal, Universidade Federal do Piauí, Brasil Ana Carolina Rocha Pessôa Temer, Universidade Federal de Goiás, Brasil André Luiz Martins Lemos, Universidade Federal da Bahia, Brasil Angela Cristina Salgueiro Marques, Universidade Federal de Minas Gerais, Brasil Ângela Freire Prysthon, Universidade Federal de Pernambuco, Brasil Anna Cristina Pertierra, Western Sidney University - Australia Antonio Carlos Hohlfeldt, Pontifícia Universidade Católica do Rio Grande do Sul, Brasil Arthur Ituassu, Pontifícia Universidade Católica do Rio de Janeiro, Brasil Bruno Campanella, Universidade Federal Fluminense, Brasil Bushra Rahman, University of the Punjab, Paquistão Cláudio Novaes Pinto Coelho, Faculdade Cásper Líbero, Brasil Cárlida Emerim, Universidade Federal de Santa Catarina, Brasil Carlos Del Valle Rojas, Universidad de La Frontera, Chile Carlos Eduardo Franciscato, Universidade Federal de Sergipe, Brasil Danilo Rothberg, Universidade Estadual Paulista, Brasil Denise Tavares da Silva, Universidade Federal Fluminense, Brasil Diógenes Lycarião, Universidade Federal do Ceará, Brasil Doris Martines Vizcarrondo, Universidad de Porto Rico, Porto Rico Eduardo Vicente, Universidade de São Paulo, Brasil Eliza Bachega Casadei, Escola Superior de Propaganda e Marketing - SP, Brasil Elvira Gomes dos Reis, Universidade do Cabo Verde, Cabo Verde Eneus Trindade, Universidade de São Paulo, Brasil Erick Felinto de Oliveira, Universidade do Estado do Rio de Janeiro, Brasil Erick Torrico, Universidad Andina Simón Bolívar, Bolívia Erly Vieira Júnior, Universidade Federal do Espírito Santo, Brasil Fabio La Rocca, Université Paul Valéry Montpellier III, França Fernando Firmino da Silva, Universidade Federal da Paraíba, Brasil Francisco de Assis, FIAM-FAAM Centro Universitário, Brasil Francisco Elinaldo Teixeira, Universidade Estadual de Campinas, Brasil Francisco Gilson R. Pôrto Jr., Universidade Federal do Tocantins, Brasil Francisco Sierra Caballero, Ciespal, Equador

Frederico de Mello Brandão Tavares, Universidade Federal de Ouro Preto, Brasil Gabriela Reinaldo, Universidade Federal do Ceará, Brasi Gérman Rey, Pontifícia Universidad Javeriana, Colômbia Gilson Vieira Monteiro, Universidade Federal do Amazonas, Brasil Gustavo Daudt Fischer, Universidade do Vale do Rio dos Sinos, Brasil Gustavo Hernández Díaz, Universidad Central de Venezuela, Venezuela Heidi Figueroa Sarriera, Universidad de Puerto Rico, Porto Rico Ignacio Aguaded, Universidad Huelva, Espanha

Inesita Soares de Araújo, FIOCRUZ, Brasil Itania Maria Mota Gomes, Universidade Federal da Bahia, Brasil Jiani Adriana Bonin, Universidade do Vale do Rio dos Sinos, Brasil João Carlos Correia, Universidade de Beira Interior, Portugal Jonathan Cohen, da University of Haifa, Israel José Afonso da Silva Junior, Universidade Federal de Pernambuco, Brasil José Luiz Aidar Prado, Pontifícia Universidade Católica de São Paulo, Brasil Josette Maria Monzani, Universidade Federal de São Carlos, Brasil Juçara Gorski Brittes, Universidade Federal de Ouro Preto, Brasil Julián Durazo Herrmann, Université du Québec à Montréal Juliana Freire Gutmann, Universidade Federal da Bahia, Brasil
Karla Covarrubias, Universidad de Colima, México Laura Loguercio Cánepa, Universidade Anhembi Morumbi, Brasil Leonel Azevedo de Aguiar, Pontifícia Universidade Católica do Rio de Janeiro, Brasi Letícia Cantarela Matheus, Universidade do Estado do Rio de Janeiro, Brasil Ling Chen, Hong Kong Baptist University Luciana Coutinho Souza, Universidade de Sorocaba, Brasil Maria Ataide Malcher, Universidade Federal do Pará, Brasil Maria Elena Hernández Ramírez, Universidad de Guadalajara, México Maria Elisabete Antonioli, Escola Superior de Propaganda e Marketing - SP, Brasil Maria das Graças Pinto Coelho, Universidade Federal do Rio Grande do Norte, Brasil Maria Teresa Quiroz, Universidad de Lima, Peru Marialva Carlos Barbosa, Universidade Federal do Rio de Janeiro, Brasil Marina Poggi, Universidad Nacional de Quilmes, Argentina Marcel Vieira Barreto Silva, Universidade Federal da Paraíba, Brasil Marcia Tondato, Escola Superior de Propaganda e Marketing, Brasil Marli Santos, Universidade Metodista de São Paulo, Brasil Márcio Souza Gonçalves, Universidade do Estado do Rio de Janeiro, Brasil Mateus Yuri Passos, Universidade Metodista de São Paulo, Brasil Mauricio Mario Monteiro, Universidade Anhembi Morumbi, Brasil Mayka Castellano, Universidade Federal Fluminense, Brasil Mirna Varela, Universidad de Buenos Aires, Argentina Mozahir Salomão Bruck, Pontifícia Universidade Católica de Minas Gerais, Brasil Neyla Pardo, Universidad Nacional de Colombia, Colombia Nísia Martins Rosario, Universidade Federal do Rio Grande do Sul, Brasil Olga Guedes Bailey, Nottingham Trent University, Inglaterra Paolo Demuru, Universidade Paulista, Brasil Paolo Peverini, L.O.U.I.S.S de Roma, Itália

Paško Bilić, Institute for Development and International Relations, Croácia Paula Melani Rocha, Universidade Estadual de Ponta Grossa, Brasil Potiguara Mendes Silveira Jr, Universidade Federal de Juiz de Fora, Brasil Priscila Ferreira Perazzo, Universidade Municipal de São Caetano do Sul, Brasil Rafael Cardoso Sampaio, Universidade Federal do Paraná, Brasil Rafael Tassi Teixeira, Universidade Tuiuti do Paraná, Brasil Regiane Lucas Garcês, Universidade Federal de Minas Gerais, Brasil Regiane Regina Ribeiro, Universidade Federal do Paraná, Brasil Renata Pitombo Cidreira, Universidade Federal do Recôncavo da Bahia, Brasil Renato Essenfelder, Escola Superior de Propaganda e Marketing, Brasil Roberto Elísio dos Santos, Universidade Municipal de São Caetano do Sul, Brasil Robson Borges Dias, Universidade Católica de Brasília (UCB), Brasil Rodolfo Rorato Londero, Universidade Estadual de Londrina, Brasil Rosario Sánchez Vilela, Universidad Católica del Uruguay, Uruguai Roseli Figaro, Universidade de São Paulo, Brasil

Saima Saeed, Jamia Millia Islamia, India Sara Brandelero, Leyden University, Holanda

Simone Maria Andrade Pereira de Sá, Universidade Federal Fluminense, Brasil Sônia Caldas Pessoa, Universidade Federal de Minas Gerais, Brasil Sun Sun Lim, Singapore University of Technology and Design, Singapura Tatiana Oliveira Siciliano, Pontifícia Universidade Católica do Rio de Janeiro, Brasil Thaïs de Mendonça Jorge, Universidade de Brasília, Brasil Valquiria Michela John, Universidade Federal do Paraná, Brasil Vicki Mayer, Tulane University, Estados Unidos Yamile Haber Guerra, Universidad de Oriente, Cuba 


\section{CONSELHO CIENTÍFICO}

Cristiane Freitas Gutfreind, Pontifícia Universidade Católica do Rio Grande do Sul, Brasil I Eduardo Antônio de Jesus, Universidade Federal de Minhas Gerais, Brasil | Eduardo Morettin, Universidade de São Paulo, Brasil I Irene de Araújo Machado, Universidade de São Paulo, Brasil | Miriam de Souza Rossini, Universidade Federal do Rio Grande do Sul, Brasil

\section{COMISSÃO EDITORIAL}

Igor Pinto Sacramento, Universidade Federal do Rio de Janeiro, Brasil । Kelly Cristina de Souza Prudencio, Universidade Federal do Paraná, Brasil । Osmar Gonçalves dos Reis Filho, Universidade Federal do Ceará, Brasil I Rafael Grohmann, Faculdade Cásper Líbero, Brasil I Thaiane Moreira de Oliveira, Universidade Federal Fluminense, Brasil (editores associados)

\section{CONSULTORES AD HOC}

Alessandro Constantino Gamo, Universidade Federal de São Carlos (UFSCAR) | Amanda Mauricio Pereira Leite, Universidade Federal do Tocantins (UFT) | Amílcar Almeida Bezerra, Universidade Federal de Pernambuco (UFPE) I Ana Carolina Damboriarena Escosteguy, Universidade Federal de Santa Maria (UFSM) I Ana Luiza Coiro Moraes, Faculdade Cásper Líbero | Antonio Pacca Fatorelli, Universidade Federal do Rio de Janeiro (UFRJ) | Ariane Diniz Holzbach, Universidade Federal Fluminense (UFF) I Benjamin Picado, Universidade Federal Fluminense (UFF) I César Augusto Baio dos Santos, Universidade Federal do Ceará (UFC) I César Geraldo Guimarães, Universidade Federal de MInas Gerais (UFMG) I César Ricardo Siqueira Bolaño, Universidade de Brasília (UNB) I Ciro Marcondes Filho, Universidade de São Paulo (USP) I Felipe Simão Pontes, Universidade Estadual de Ponta Grossa I Felipe Trotta, Universidade Federal Fluminense (UFF) I Gislene da Silva, Universidade Federal de Santa Catarina (UFSC) I Kati Caetano, Universidade Tuiuti do Paraná I Laan Mendes de Barros, Universidade Estadual Paulista Júlio de Mesquita Filho I Lucia Leão, Pontifícia Universidade Católica de São Paulo (PUC-SP) I Jairo Getulio Ferreira, Universidade do Vale do Rio dos Sinos (UNISINOS) | Juliana Doretto, FIAM-FAAM | Juliano Maurício de Carvalho, Universidade Estadual Paulistaa Júlio de Mesquita Filho | Lilian Cristina Monteiro França, Universidade Federal de Sergipe I Liziane Soares Guazina, Universidade de Brasília (UNB) I Luís Mauro Sá Martino, Faculdade Cásper Líbero I Luiz Peres Neto, Escola Superior de Propaganda e Marketing (ESPM) I Herom Vargas, Universidade Metodista de São Paulo I Inês Silvia Vitorino Sampaio, Universidade Federal do Ceará (UFC) I Maria Helena Weber, Universidade Federal do Rio Grande do Sul (UFRGS) I Mariana Baltar, Universidade Federal Fluminense (UFF) I Maurício de Bragança, Universidade Federal Fluminense (UFF) I Mauro de Souza Ventura- Universidade Estadual Paulista Júlio de Mesquita Filho I Muniz Sodre de Araujo Cabral, Universidade Federal do Rio de Janeiro (UFRJ) I Nuno Manna, Universidade Federal da Bahia (UFBA) I Rosana de Lima Soares, Universidade de São Paulo (USP) I Sandra Maria Lúcia Pereira Gonçalves, Universidade Federal do Rio Grande do Sul (UFRGS) I Sérgio Luiz Gadini, Universidade Estadual de Ponta Grossa I Talitha Gomes Ferraz, Escola Superior de Propaganda e Marketing (ESPM) I Victa de Carvalho Pereira da Silva, Universidade Federal do Rio de Janeiro (UFRJ)

\section{EQUIPE TÉCNICA}

ASSISTENTES EDITORIAL Melina Santos | REVISÃO DE TEXTOS Fátima Áli | EDITORAÇ̃̃o ELETRÔNICA Roka Estúdio

COMPÓS I www.compos.org.br

Associação Nacional dos Programas de Pós-Graduação em Comunicação

Presidente

Marco Roxo

Programa de Pós-Graduação em Comunicação - UFF marcos-roxo@uol.com.br

Vice-Presidente

Isaltina Gomes

Programa de Pós-Graduação em Comunicação - UFPE

isaltina@gmail.com

Secretária-Geral

Gisela Castro

Programa de Pós-Graduação em Comunicação

e Práticas de Consumo - ESPM

castro.gisela@gmail.com

CONTATO I revistaecompos@gmail.com 